\title{
Diagnosis and numerical simulations of a heavy rain event in the Western Mediterranean Basin
}

\author{
D. Santos-Muñoz ${ }^{1}$, M. L. Martín ${ }^{2}$, M. Y. Luna ${ }^{1}$, and A. Morata ${ }^{1}$ \\ ${ }^{1}$ Instituto Nacional de Meteorología, Madrid, Spain \\ ${ }^{2}$ Dpto. Matemática Aplicada, Escuela de Informática, Campus de Segovia, Universidad de Valladolid, Spain \\ Received: 7 October 2005 - Revised: 3 January 2006 - Accepted: 23 January 2006 - Published: 14 February 2006
}

\begin{abstract}
The heavy rain event of November 2001 in the western Mediterranean area was synoptically characterized by the presence of a long-lived Omega blocking geopotential pattern. A set of mesoscale numerical simulations using MM5 is performed to investigate the mechanisms responsible for the convection development through several output diagnosis. A potential vorticity evolution showed how dry air masses were extruded from the stratospheric levels promoting strong cyclonic circulation at all levels. Moreover, a deep vertical column of high relative humidity over the Algerian coastline maintained the few and geographically confined convective cells responsible for the heavy precipitation. Mesoscale environment parameters indicated enhanced conditional instability through a deep troposphere layer. Also, strong vertical wind shear values, higher than $50 \mathrm{~ms}^{-1}$ over the troposphere, were derived, indicating enough strength to promote necessary conditions to organize and keep mesoscale convective structures.
\end{abstract}

\section{Introduction}

The closed characteristic of the Mediterranean Sea and the high insolation received during long part of year lead to high sea surface temperatures during summer and autumn which ensure warm, moist air that can be raised over the orography. This situation favors instability and the release of vast amounts of latent heat. The result is the development of thunderstorms which may be a single supercell, a squall line or even secondary cyclones (Font, 2000). This paper is devoted to analyze the temporal evolution of the synoptic and mesoscale features conducing to the heavy rain episode of 8 to 21 November 2001 in the Western Mediterranean area. Heavy precipitation mainly affected the northern of Africa and the Balearic Islands, with particularly heavy 24-h rainfall totals on 10 November over Algeria and on 11 November

Correspondence to: M. Y. Luna

(yluna@inm.es) over the Balearic Islands. MM5 numerical simulations were used to identify the key factors that explain the event.

\section{Diagnostic methodology}

The non-hydrostatic mesoscale model (MM5, version 3) of the Pennsylvania State University-National Center of Atmospheric Research is used (Anthes and Warner, 1978; Grell et al., 1994). It is formulated using the terrain following $\sigma$ coordinate system and the details of the physical parameterizations can be found in the references. The model has two-way interaction between successive nesting levels that allows realistic terrain characteristics. Figure 1a shows the fine grid domain centred in the eastern Iberia and its orography. This domain measures $1720 \times 1510 \mathrm{~km}$ under a Lambert conformal map projection ( $10 \mathrm{~km}$ to horizontal spacing). Figure $1 \mathrm{~b}$ shows the selected coarse domain that measures $4530 \times 3030 \mathrm{~km}$ and is centered at the same location. The time steps are chosen as 30 and $90 \mathrm{~s}$ for the fine and coarse grids, respectively. The initial and boundary conditions for the coarse grid are taken from NCEP global reanalysis data (available at 00:00, 06:00, 12:00 and 18:00 UTC) with a resolution of 2.5 degrees. Two simulations for each day have been performed from 00:00 and 12:00 UTC till 00:00 and 12:00 UTC (next day), respectively. The integrations start at 00:00 UTC on 8 November 2001 and finish at 00:00 UTC 22 November 2001.

\section{Diagnosis of the case of November 2001}

The rainfall maximum for the event was recorded in the $\mathrm{Al}-$ geria coastline and exceeded $300 \mathrm{~mm}$ on 10 and 11 November with $140 \mathrm{~mm}$ on only six hours (Fig. 2). The synoptic configuration reflects a blocking pattern named "Omega block" with a zonally oriented configuration of a high situated over western British Island in between two lows. The main low was located at southern Genoa Gulf with an associated front. At $300 \mathrm{hPa}$, a jet streak crossing from the 

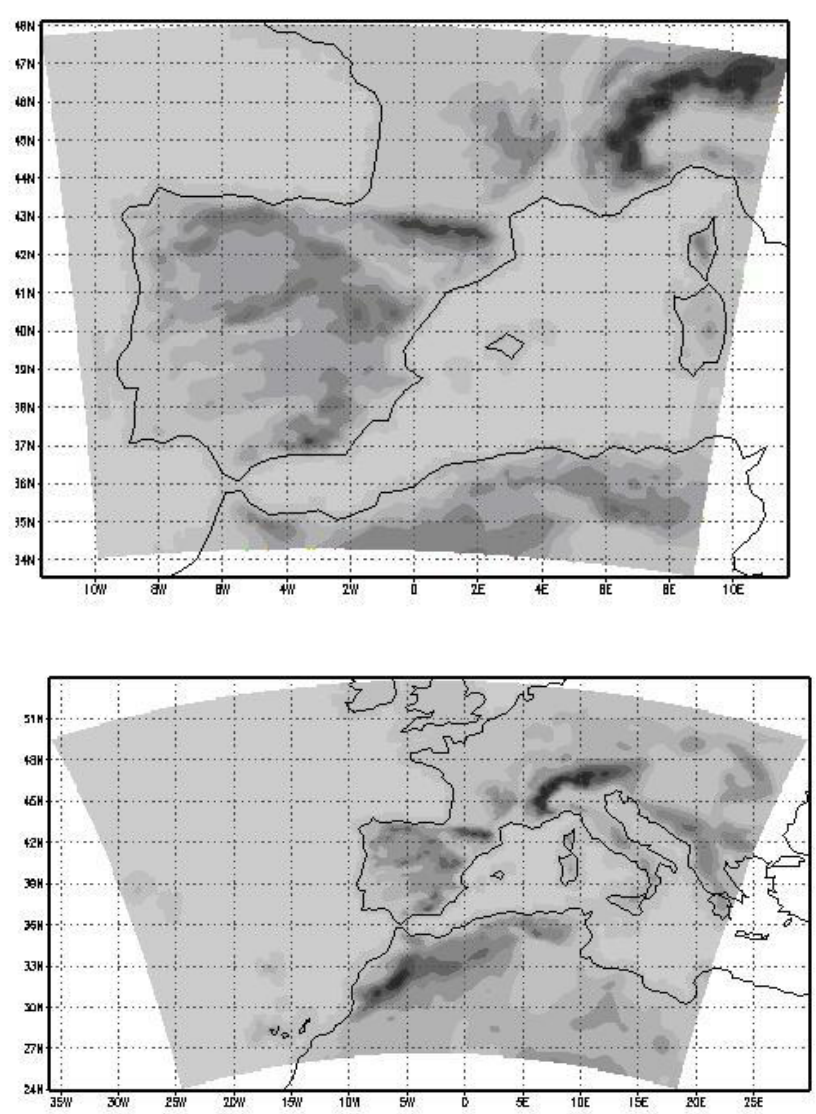

Fig. 1. (a) The used centered fine grid domain and its orography; (b) The selected coarse domain.

north of Africa to western Mediterranean was noticeable, driving large-scale instability conditions. The upper level winds were intense and nearly perpendicular to Atlas mountain ridge encouraging the instability conditions. More details of the synoptic description can be found in Genoves and Jansa (2002) and Tripoli et al. (2005).

A Potential Vorticity (PV) evolution from 8 to 12 November at $300 \mathrm{hPa}, 12: 00$ UTC (Fig. 3) reflects a strong pool that progresses from the high latitudes to the western and central Mediterranean area, from the NW Iberia to the northern Africa. There are remarkably high values of PV units (higher than $8 \mathrm{PVU}$ ), which indicate lowering of the dynamical tropopause and intrusions of stratospheric air. In this situation, rapid pressure falls occurred at low levels in juxtaposition with the upper level jet streak. The associated positive (negative) PV advection is situated ahead (rear) of the PV anomaly, indicating that quasigeostrophic forcing for vertical upward (downward) motions will occur owing to the increase of such advection with height. Consistent with the jet-induced upward forcing features, the model diagnoses upward vertical velocity throughout the troposphere. On 9 November at 18:00 UTC (Fig. 4a), it can be noted a vigorous plume of upward motion extending from surface to $300 \mathrm{hPa}$ over a narrow area of northern Africa. Another significant feature is the existence of a deep vertical column of high rel-
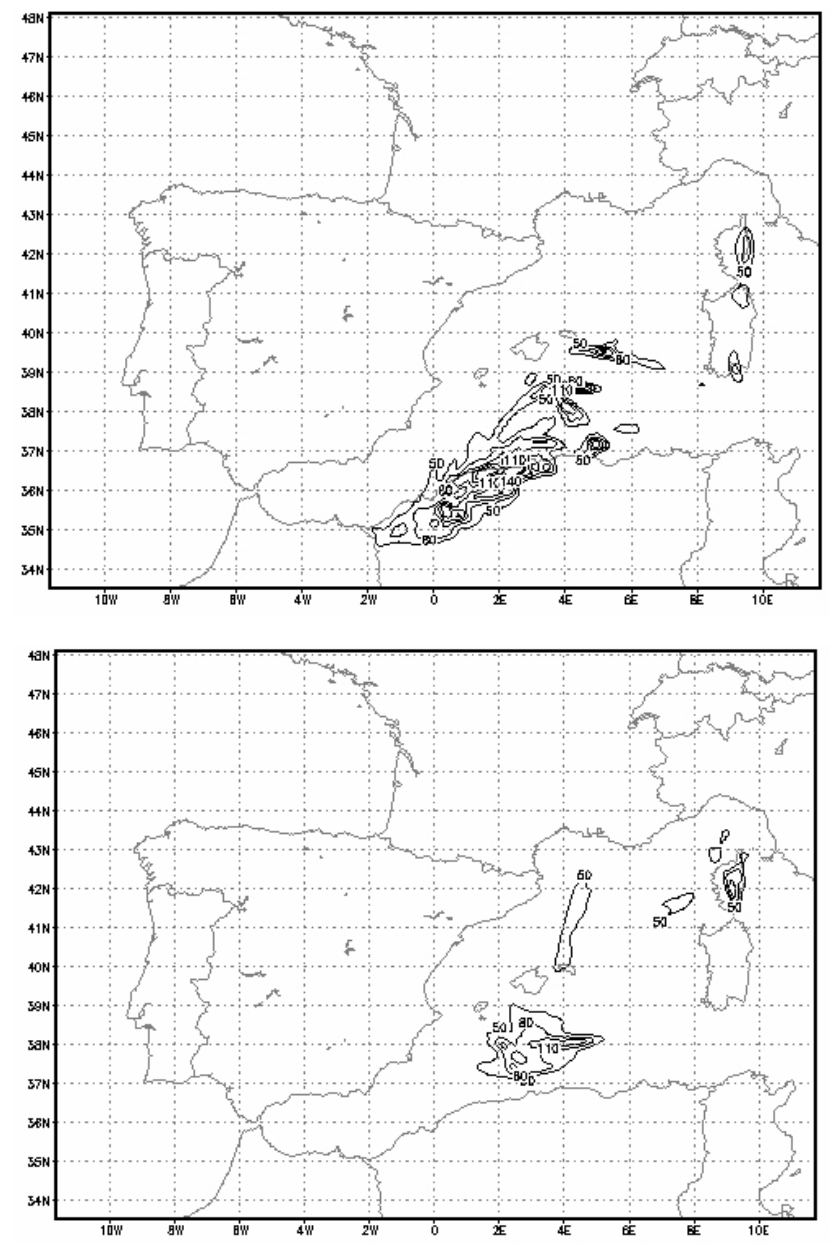

Fig. 2. 24-h precipitation in the western Mediterranean basin: (a) 10 November 2001; (b) 11 November 2001. Contours every $50 \mathrm{~mm}$, starting in $50 \mathrm{~mm}$.

ative humidity spanning over the Algerian coastline which keeps the few and geographically confined convective cells responsible for the heavy precipitation. On 11 November at 06:00 UTC (Fig. 4b), it is highlighted another centre of intense upward motion over the Balearic area with a high relative humidity column throughout the troposphere over the same zone. Lower relative humidity values (not shown) are present over western Iberia according with the dry air extruded from the stratospheric levels associated with the PV anomalies. On the contrary, higher values of relative humidity can be observed over the Atlas Mountains and the Spanish Mediterranean littoral coinciding with an area of vertical upward motions.

Standard tools of convective storm analysis, such as the totals-totals index (TTI), the lifted index (LI) and the $\mathrm{K}$ index $(\mathrm{KI})$, have been obtained from the simulations and they showed an enhanced conditional instability through a deep troposphere layer. Throughout the episode, large values of vertical wind shear higher than $50 \mathrm{~ms}^{-1}$ over the troposphere were derived, indicating enough strength to promote necessary conditions to organize and maintain long-lived supercell 

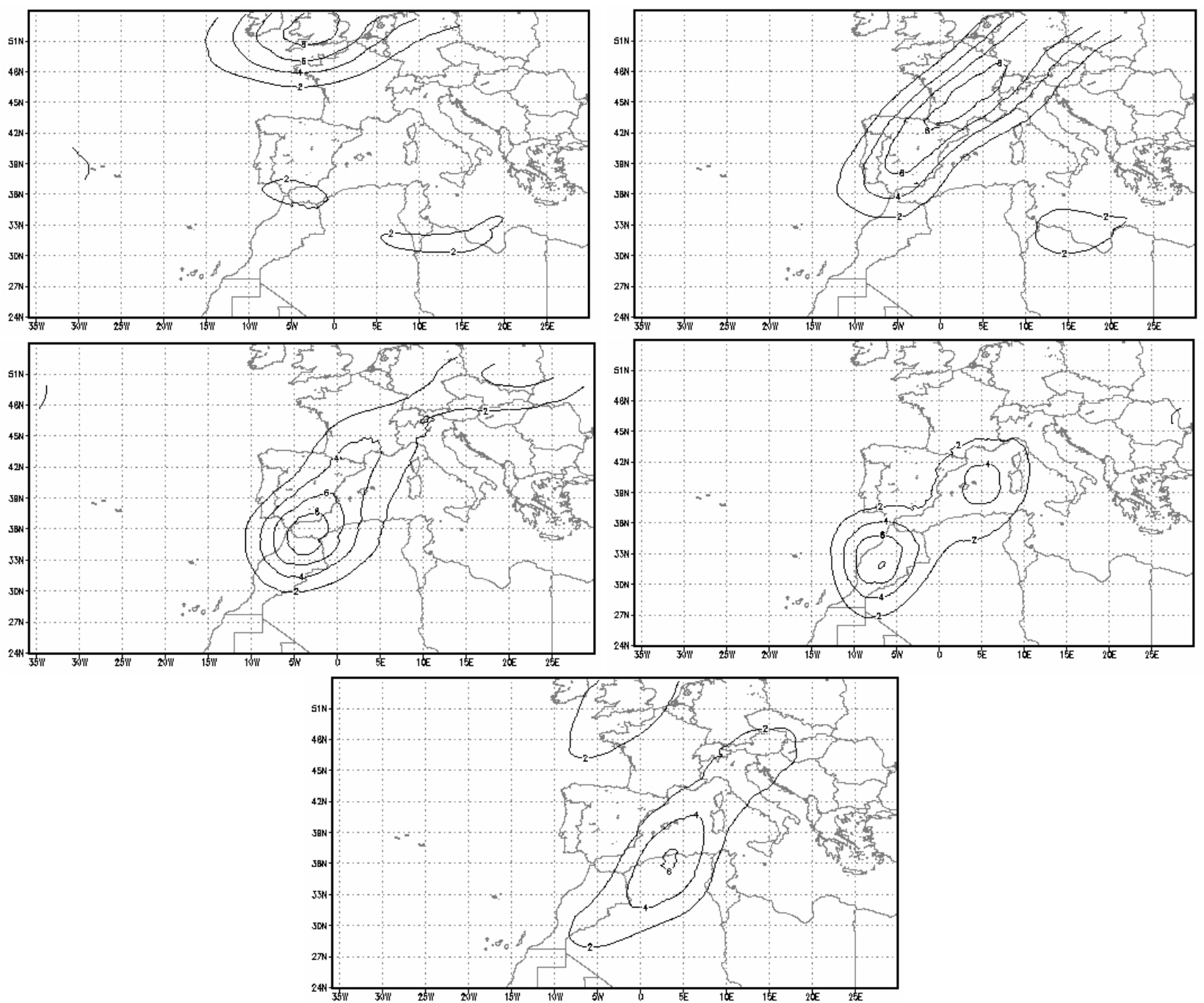

Fig. 3. Diagnosed Potential Vorticity at $300 \mathrm{hPa}, 12: 00$ UTC: (a) 8 November; (b) 9 November; (c) 10 November; (d) 11 November and (e) 12 November 2001. Interval contour is $2 \mathrm{PVU}\left(10^{-6} \mathrm{~m}^{2} \mathrm{~s}^{-1} \mathrm{~K} \mathrm{~kg}^{-1}\right)$ starting in $2 \mathrm{PVU}$.

convective structures. The values of the convective available potential energy (CAPE) were high, extending the affected zone from Algeria, on 9 November with values higher than $1000 \mathrm{~J} \mathrm{~kg}^{-1}$, to the Balearic area on 11 November with values of up to $800 \mathrm{~J} \mathrm{~kg}^{-1}$, and reflecting intense vertical motions of individual air parcels.

\section{Conclusions}

The explosive storm development over the western Mediterranean area was due to a number of factors all coming together at the same place and time. The contribution from the large-scale conditions was crucial. A synoptic critical control was the blocking omega pattern that promoted the channeling effect. This synoptic scenario acted to induce mass ascent and release of conditional instability. Moreover, the lifting on the Atlas Mountain and the Balearic orography together with the front associated with the main low contributed to additional mesoscale ascent and subsequently severe weather. The MM5 numerical analysis identified air masses marked by strong upper-level PV stretching to increase relative vorticity, which augments deepening of a cyclone. Ahead of the PV maximum, the increase of positive vorticity advection with height favored vertical upward motions, resulting on a mesoscale convective system.

Acknowledgements. This work has been partially supported by the research project CGL2004-01584/CLI. The authors wish to thank to the NOAA-CIRES Climate Diagnostics Center, Boulder, Colorado, USA for the NCEP Reanalysis data. We are also very much indebted to the referees for their helpful discussions concerning this work.

Edited by: V. Kotroni and K. Lagouvardos

Reviewed by: anonymous referee 

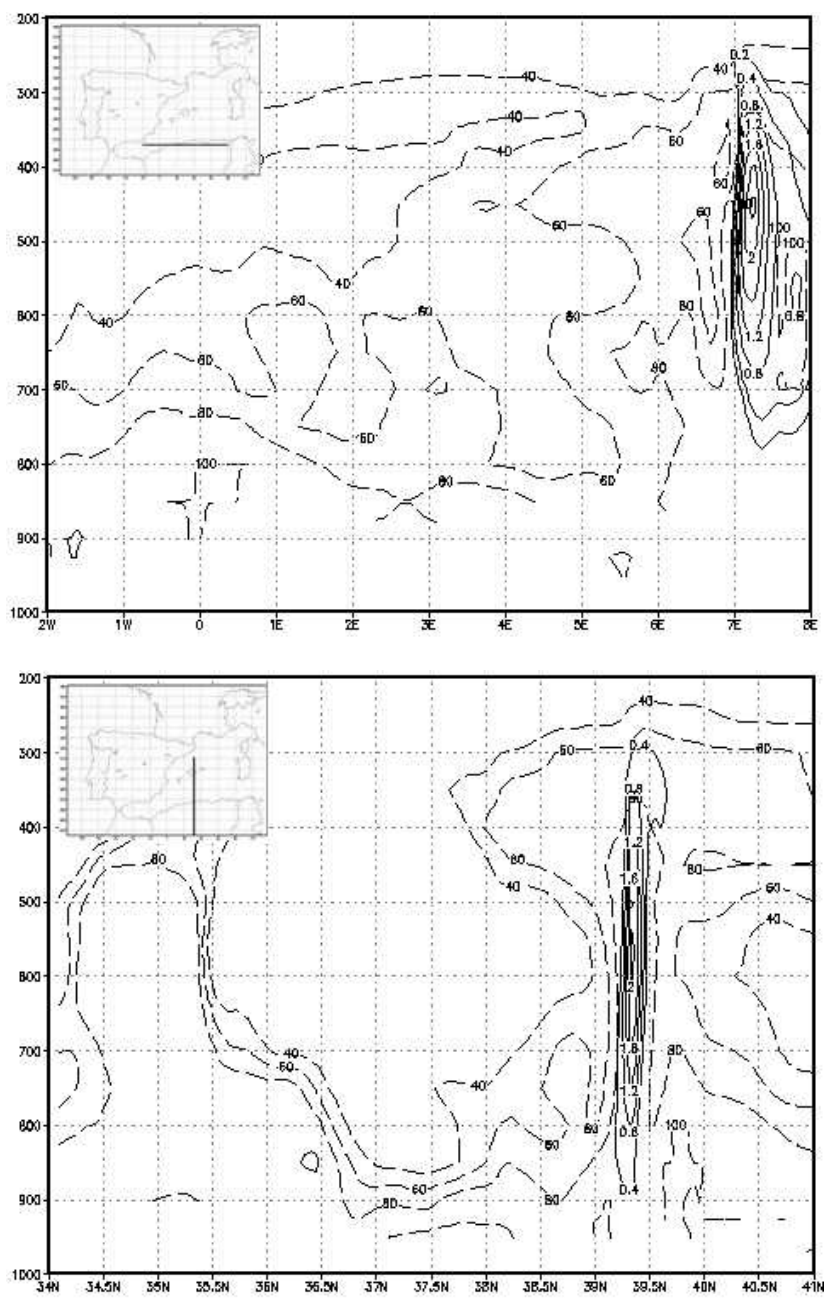

Fig. 4. Vertical cross section showing relative humidity (contours every $20 \%$, starting in 40 , dashed line) and upward vertical velocity (contour interval is $0.4 \mathrm{~ms}^{-1}$, starting in 0.4 , continuous line): (a) 9 November, 18:00 UTC; (b) 11 November, 06:00 UTC. The cross sections are realized along the lines indicated in the corresponding upper left corner map.

\section{References}

Anthes, R. A. and Warner, T. T.: Development of hydrodynamic models suitable for air pollution and other mesometeorological studies, Mon. Wea. Rev., 106, 1054-1078, 1978.

Font, I.: Climatología de España y Portugal, 2nd ed. Ed. Universidad de Salamanca, Spain, 2000.

Genovés, A. and Jansá, A.: Diabatic processes contribution to the November 2001 storm, Proc. 4th EGS Plinius Conference, Mallorca, Spain, 2002.

Grell, G. A., Dudhia, J., and Stauffer D. R.: Diagnosing coupled jet streak circulations for a northern plains snow band from the operational nested-grid model, Wea. Forecast., 7, 26-48, 1994.

Tripoli, G. J., Medaglia, C. M., Dietrich, S., Mugnai, A., Panegrossi, G., Pinori, S., and Smith, E. A.: The 9-10 November 2001 Algerian flood, Bull. Amer. Meteorol. Soc., 86, 1229-1235, 2005. 